Pegem Journal of Education \& Instruction, 4(1), 2014, 27-46

Pegem Eğitim ve Öğretim Dergisi, 4(1), 2014, 27-46

www.pegegog.net

\title{
An Investigation of English Language Instructors' Attitudes towards Reflective Teaching
}

\author{
Mithat KORUMAZ ${ }^{\mathrm{a}^{*}}$, Ali KARAKAŞ ${ }^{\mathrm{b}}$ \\ ${ }^{a}$ Yıldız Technical University, Faculty of Education, İstanbul/Turkey \\ ${ }^{\mathrm{b}}$ Mehmet Akif Ersoy University, Faculty of Education, Burdur/Turkey
}

\section{Article Info}

DOI: $10.14527 /$ pegegog.2014.002

Article history:

Received 25 April 2013

Revised 14 October 2013

Accepted 02 January 2014

Keywords:

Reflective teaching,

English language teaching,

Reflection,

Professional growth.

\begin{abstract}
This study is predicated on a descriptive survey of quantitative research designs, which attempts to identify the attitudes of instructors of English towards reflective teaching in Turkey. For the collection of data, Reflective Teaching Attitude Scale, developed by Akbari, Bahzaadpoor and Dadvand, was distributed to 56 instructors of English who comprised the sampling of the study. The instructors were sampled more than ten universities across Turkey. The questionnaire was administered via using the online questionnaire feature of Google documents. The results demonstrate that all instructors tend to hold positive attitudes towards reflective teaching. In addition, when some variables such as gender, types of institutions worked at, faculties graduated from, and finally the last degree they hold are concerned, no statistically significant difference is observed among the participants in relation to their attitudes towards reflective teaching.
\end{abstract}

\section{Introduction}

In order to increase the effectiveness of teaching and learning in different areas of education, many studies have been undertaken hitherto. One of the focal questions posed in previous studies is the question of 'what is effective learning or teaching? Different responses have been sought to this question from various philosophical, theoretical, application-centric perspectives (Ekiz \& Yiğit 2007).

Discussions and recommendations have arisen from time to time regarding what needs to be done for the purpose of training effective teachers who can plan, implement and evaluate learning and teaching in order to better perform effective teaching and learning (Ekiz \& Yigit, 2006). Some accounts towards teacher candidates' learning and using theoretical knowledge such as how teacher candidates learn how to teach, what they value in the process of teaching, what they have adopted, which knowledge (theory or practice-based) they effectively use are given in these discussions and recommendations.

Trends related to the training of teachers or teacher training have been largely altered from past to present. The changes that were experienced within a short time can be considered as a reflection of educational paradigms which centralize individuals. In parallel, teacher education programs have, in recent years, transformed into individual-cantered structures in line with the requirements of the current era, and teacher-training programs have shifted towards being application-based studentcentred approach rather than from being theory-based teacher-centred approach (Kılıç, 2006).

\footnotetext{
* Corresponding author: mkorumaz@yildiz.edu.tr
} 
Until today, widely accepted teacher training models have been theory-based model of teacher training, teacher training based on humanistic theory and teacher training based on the constructivist theory. Yet, in practice, there are three general teacher education models that have manifested themselves markedly so far. These models are applied-science, skills-based and reflective models (Wallace, 1991).

At the core of the skills-based model lies the approach of 'learning by doing'. This model argues for the fact that teacher knowledge and skills could only be acquired through observation and experience (Smith, 1999). The applied-science model that has been attempted to be developed and implemented from the 1950s bases its implementations on the findings in educational psychology. This model is also known as the rational approach (Ekiz \& Yiğit, 2006). According to Laursen (1996), this model is based on the principle of transformation of learning theories formulated in the field of behavioural psychology into effective teaching methods. This model advocates the view that scientific research data on education should be utilized in teaching and learning practices.

According to the reflective model, a teacher candidate is expected to effectively use the knowledge he/she has theoretically learned, and to apply the skills and knowledge that he/she has obtained in relation to teaching experience. The teacher candidate who benefits from both the knowledge learned and gained through experiences makes implementations in any school or classroom environment. The candidate, persistently, effectively and in a systematic manner, reflects on any problems encountered in practice in order to eliminate the problem or make the implementation more effective, taking into consideration the theoretical knowledge acquired. The candidate, again, reuses new knowledge and skills configured as a result of his/her reflection and thinking. And this cycle continues in the same manner. After performing reflective thinking and teaching, the candidate gains the professional qualifications and then becomes a teacher (Ekiz, 2003). The most prominent feature of reflective model is to both make use of information produced by scientific research, and include this information through questioning by the teacher candidate or teacher in the decision making process while transmitting them into practice (Ekiz \& Yiğit, 2007).

Recently, many research studies have been conducted on the concept of 'reflection'. But, as the studies conducted on this concept itself and reflective teaching founded on the basis of this concept are limited to the teacher candidates and teachers, and to primary and secondary education institutions, they are far from being adequate (eg: Amobi, 2005; Filiz, 2008; Lee, 2007; Montenegro, 2010; Pedro , 2005). Whilst Schön (1983) initially focused on two types of reflection, 'reflection on the action' (about teaching) and 'reflection in action' (in teaching), he later proposed the concept of 'reflection for action' (for teaching), a third-type of reflection. Reflection on action (teaching) is the reflection of the implemented teaching activities in a systematic and consistent process in order to shed light on the next actions or for the planning of subsequent activities after the teaching activities have been realized. The important point in this kind of reflection is the conduct of reflection immediately after the act of teaching (Schön, 1983). Reflection (in teaching) in action refers to the process of making decisions and reflection while the act of teaching is taking place. According to Schon (1987), reflection in action is the act of thinking about the teaching while it is being carried out in the classroom. In this sense, reflection is context-based (Day, 1999). It is quite crucial for the teacher to reflect on his teaching behaviours taking into account the context he acts in. It means a lot more than thinking about what we do as teachers. Reflection requires instant analysis and reasoning ability, and that is why many researchers are of the opinion that this type of teaching and application is much more difficult (Waters, 2005). Reflection (for teaching) action refers to a cognitive process that will create opportunities for those who want to conduct reflective applications to be able to better plan the recalls they have already obtained so far, and what they will do in the next stages. The ideal thing in this type of reflection is the inclusion of pedagogical theories that allow for the analysis of critical pedagogy, and different perspectives of teachers with respect to teaching (Weshah, 2007). 
Reflective teaching areas are composed of three different areas: technical, application and critical areas. The most basic area for reflective teaching is the technical reflection area. The increase of knowledge on theory and application, the expansion of the reflective teaching areas, and application and criticality being the top-tier reflection areas are considered a prerequisite in shifting towards reflection (Taggart, 2005).

Now that reflective teaching is defined as making a set of changes in acts by reflecting on what have been done in the context of learning and teaching, both teachers and students are required to collect information about learning and teaching contexts. Data for reflection are collected by different tools of reflective teaching. Related reflective teaching tools may be used individually, or might be used in combinations in order to obtain depth information. Some of the reflective teaching tools are as follows: teaching diaries, course reports, research and surveys, action research, observation, sound and video recordings, peer counselling and teaching debates (Richards, 1995).

Recently, the number of studies on the types of reflective teaching, its areas and the use of reflective teaching tools has dramatically increased all over the world. The skyrocketing increase in the number of studies on reflective teaching indicates that reflective teaching has become more and more important. Some of these studies have focused on lecturers' perspectives, who are based in higher education institutions. For example, Amobi (2005) reported that lecturers defined reflective teaching as 'a way of mirroring on teaching', and 'being fearless in having different perspectives on any particular issue and being willing to be fearless'. Studies addressed other teachers and pre-service teachers in various contexts, as well (e.g. Filiz, 2008; Karadağ, 2010; Lee, 2007; Pedro, 2005). In light of the above discussion, this paper aims to address the following research questions:

1. Do English language instructors differ in their attitudes to reflective teaching according to their gender?

2. Do English language instructors differ in their attitudes to reflective teaching according to the type of university (public or private) they work at?

3. Do English language instructors differ in their attitudes to reflective teaching according to the faculty type (Education or Science and Literature) they graduated from?

4. Do English language instructors differ in their attitudes to reflective teaching according to the last degree (BA or MA) they completed

\section{Method}

\section{Research Design}

In this descriptive research, a survey approach was utilized. Survey methods are an approach that aims to describe any case which existed in the past or still exists as they were or are. The case or any individual or object being the topic of the research is attempted to be described in their own conditions (Karasar, 2008). This research sets out to explore English language instructors' attitudes towards reflective teaching.

\section{Participants}

Fifty six English language instructors, from a large number of universities, including public and private institutions took part in the study. Due the small number of participants, a caution should be exercised in regards to the generalization of the research findings. Of all the participants, 18 were male and 38 female lecturers. Among all participants, 34 were working in a public university, while the rest, 22, were based in private universities at the time of data collection. As for the faculties they graduated, 35 of the participants were from faculty of education, whereas 21 were from faculty of science and letters. Concerning the last degree they held, 42 instructors held a Bachelor's degree, while 24 held 
Master's. In respect of their years of teaching, 39 had a working experience of 1-5 years, and 17 instructors reported to work as English language instructors at least more than 6 years. Finally, when the average number of their students per class was considered, 35 of them worked in class of 20 students, 16 instructors in a class of 10-20, and 9 in a class which had more than 31 students.

\section{Instrument}

An attitude scale developed by Akbari, Bahzadpoor and Dadvand (2010) for measuring English language instructors' reflective teaching attitudes was used in the study as the main tool of data collection. The attitude scale was modified and translated into Turkish from English by Korumaz (2012). The attitude scale is made up of a total of 29 questions and five sub-dimensions which are application, cognition, student, meta-cognition and criticality dimensions. The questionnaire consisted of five-point Likert scale ranging from "strongly agree" to "strongly disagree".

\section{Data Analysis}

For the purpose of analysing the collected data, the statistical software package SPSS for windows (version 16.0) was used for all data entry and further statistical analyses. Prior to conducting any statistical tests, the test of normality was carried out and the required conditions were met to run statistical analysis on the data. Statistical procedures included descriptive statistics and independent samples t-test. In the interpretation of the findings, the significance level of 0.5 for the $P$ value was taken as the valid cut-off point.

\section{Results}

In order to find out whether there is a significant difference in English language instructors' attitudes towards reflective teaching on the basis of their gender, type of university they work at (private or public), type of faculty they graduated from (education faculty or faculty of science and letters), last degree they held, an independent samples t-test was run. The obtained results are given below in the order of sub-research questions:

\section{Do English Language Instructors Differ from Each Other in Their Attitudes towards Reflective Teaching According to Their Gender?}

The result of the analysis indicated that male and female English language instructors did not have a significant difference in their attitudes to reflective teaching [ $t(54)=0,241, p>0.05$ ]. The obtained results of analysis are given in Table 1 below:

Table 1.

Results of Descriptive Statistics According to Gender.

\begin{tabular}{lcccccc}
\hline Gender & $\mathbf{n}$ & $\overline{\boldsymbol{X}}$ & $\mathbf{S}$ & $\mathbf{S d}$ & $\mathbf{t}$ & $\mathbf{p}$ \\
\hline Female & 38 & 95.29 & 11.866 & 54 & 1.185 & .241 \\
\hline Male & 18 & 99.89 & 14.275 & & & \\
\hline
\end{tabular}

Do English Language Instructors Differ from Each Other in Their Attitudes towards Reflective Teaching According to the Type University They Work at?

According to the t-test results obtained from English language instructors' attitudes towards reflective teaching, the type of university they are based in, being either a public or a private one, does not reveal any significant relationship among instructors [ $t(54)=0.246, p>0.05$ ]. The obtained results are summarized in Table 2 below: 
Table 2

t-test Results According the Type of University They Work at.

\begin{tabular}{lcccccc}
\hline University & $\mathbf{n}$ & $\overline{\boldsymbol{X}}$ & $\mathbf{S}$ & $\mathbf{S d}$ & $\mathbf{t}$ & $\mathbf{p}$ \\
\hline Private & 34 & 95.06 & 12.704 & 54 & 1.172 & .246 \\
\hline Public & 22 & 99.41 & 14.822 & & & \\
\hline
\end{tabular}

Do English language instructors differ from each other in their attitudes to reflective teaching according to the faculty type they graduated from?

As a result of the statistical analysis, no significant difference was found among English language instructors regarding their attitudes to reflective teaching according to the type of faculty they graduated from $[t(54)=0.365, p>0.05$ ]. Relevant statistical results are displayed in Table 3:

Table 3.

t-test Results According to the Type Faculty Instructors Graduated from.

\begin{tabular}{lcccccc}
\hline Faculty & $\mathbf{n}$ & $\overline{\boldsymbol{X}}$ & $\mathbf{S}$ & $\mathbf{S d}$ & $\mathbf{t}$ & $\mathbf{p}$ \\
\hline Education & 35 & 98.06 & 12.163 & 54 & .914 & .365 \\
\hline Science and Letters & 21 & 94.62 & 15.822 & & & \\
\hline
\end{tabular}

Do English Language Instructors Differ from Each Other in Their Attitudes to Reflective Teaching According to the Type of Degree They Hold?

Finally, the t-test results disclosed that there is no significant difference among English language instructors in their attitudes to reflective teaching according to the type last degree they held $[t(54)=0.801, p>0.05]$. The statistical test run and its results are presented in Table 4:

Table 4.

t-Test Results According to the Last Degree Instructors Hold.

\begin{tabular}{lcccccc}
\hline Program & $\mathbf{n}$ & $\overline{\boldsymbol{X}}$ & $\mathbf{S}$ & $\mathbf{S d}$ & $\mathbf{t}$ & $\mathbf{p}$ \\
\hline BA & 42 & 96.50 & 13.486 & 54 & .253 & .801 \\
\hline MA & 14 & 97.57 & 14.474 & & & \\
\hline
\end{tabular}

\section{Discussion, Conclusion \& Implementation}

This study attempted to find out how English language instructors employed at various Turkish universities oriented to reflective teaching, or put differently their own teaching and learning acts. In general, considering the arithmetic average of the total scores, it might be asserted that English language instructors displayed positive attitudes to reflective teaching. These findings also mirrored and were in accord with the findings of Butke (2003), Carter (1998), Filiz (2008), Goodman (1982), Karadağlı (2010), Loughran (1995), McKeny (2006), and Troyer (1989) who obtained their data from in-service teachers and teacher candidates in relation to reflective teaching. These results might be interpreted in way that these language instructors had an inclination towards reasoning and thinking in-depth about their actions before taking actions, during or after their actions. Another interpretation is concerned with the indication of their tendency to attach importance to their professional development and to critically reflect on classroom practices.

Based on the obtained results, it is seen that there is no statistical difference between language instructors' attitudes and the type of university they worked at. This finding echoed a very recent finding of Korumaz (2012) who also did not observe any statistical difference among Turkish language teachers of English. In conclusion, we might come up with the idea that irrespective of the type of institution instructors work at, their attitudes to reflective teaching do not differ significantly. As also mentioned, instructors did not differ from each other in their attitudes according to the last degree they finished. 
Less than a decade ago, however, Öztürk, Doğan and Koç (2005) and Şimşek (2011) found dissimilarities among teachers and students who graduated from an education faculty and faculty of science and letters in relation to reflective teaching attitudes. In brief, graduates of education faculty were observed to have more positive attitudes. Unlike these studies, Gürbüz and Kışoğlu (2007) discovered that teachers did not show difference in their attitudes to reflective teaching based on the faculty type, which had a similar line with our research. In short, the conclusion that lecturers' attitudes are not significantly affected by the faculty type they completed might be arrived at.

It was found that no significant difference emerged between instructors' attitudes and the last degree they earned. This led us to conclude that being a graduate of BA or MA program did not have a significant impact on English language instructors' attitudes to reflective teaching. In parallel to this result, Mutlu and Aktan (2011) did not identify any significant relationship between teachers who held a BA and MA diploma in their attitudes to critical thinking training. In light of the findings of this study, the following suggestions are made for future research:

1. In future studies, the extent to which English language instructors can use their reflective teaching skills can be determined and studies can be made to improve their skills in practice.

2. Effective in-service and pre-service training programs can be designed and administered in order to step up instructors' attitudes to reflective teaching to the highest step.

3. In studies relevant to this one, the level of language instructors' reflective teaching skills and the degree to which they can use these skills can be examined.

4. Reflective teaching strategies refer to application. The application area is the use positive attitudes held and teaching related skills. Therefore, reflective teaching skills can be a matter of research individually in future research on reflective teaching.

5. Further research can be initiated to allow for more space for reflective teaching in the training programs of teacher training institutions. 


\title{
İngilizce Okutmanlarının Yansıtıcı Öğretime Yönelik Tutumlarının İncelenmesi
}

\author{
Mithat KORUMAZ ${ }^{\mathrm{a}^{*}}$, Ali KARAKAŞ ${ }^{\mathrm{b}}$ \\ ${ }^{a}$ Yıldız Teknik Üniversitesi, Eğitim Fakültesi, İstanbul/ Türkiye \\ ${ }^{\mathrm{b}}$ Mehmet Akif Ersoy Üniversitesi, Eğitim Fakültesi, Burdur/ Türkiye
}

\section{Makale Bilgisi}

DOI: 10.14527/pegegog.2014.002

Makale geçmişi:

Geliş 25 Nisan 2013

Düzeltme 14 Ekim 2013

Kabul $\quad 02$ Ocak 2014

Anaktar kelimeler:

Yansıtıcı öğretim,

İngilizce öğretimi,

Yansitma,

Mesleki gelişim.
Öz

Bu araştırma, İngilizce okutmanlarının yansıtıcı öğretime yönelik tutumlarını belirlemek amacıyla nicel araştırma desenlerinden tarama modelinde betimsel bir araştırmadır. Verileri toplamak amacıyla Akbari, Bahzadpoor ve Dadvand tarafından geliştirilen Yansıtıcı Öğretim Tutum Ölçeği kullanılmıştır ve araştırmaya 56 İngilizce okutmanı katılmıştır. İngilizce okutmanlarının örneklemi Türkiye genelindeki ondan fazla üniversiteden elde edilmiştir. Anketler Google Belgelerin anket oluşturma özelliğinden yararlanılarak online olarak uygulanmıştır. Araştırma sonucunda okutmanların tamamının yansıtıcı öğretime yönelik tutumlarının olumlu yönde olduğu sonucuna ulaşılmıştır. Ayrıca araştırmaya katılan okutmanların cinsiyetleri, çalıştıkları kurum türü, mezun oldukları fakülte türü ve en son mezun oldukları program türüne göre ölçme aracından aldıkları puanların ortalamaları arasında anlamlı bir farklıık bulunmamıştır.

\section{Giriş}

Öğrenme ve öğretimde etkililiği artırmak amacıyla eğitimin farklı alanlarına yönelik birçok çalışma yapılmıştır. Yapılan çalışmalarda yöneltilen temel sorulardan biri, etkili öğrenme ya da öğretim nedir? sorusudur. Bu soruya, farklı felsefi, kuramsal ve uygulama-merkezli boyutlardan yaklaşılarak değişik yanıtlar aranmıştır (Ekiz ve Yiğit 2007). Temelini realizmden alan "Daimicilik” eğitim felsefesi, eğitimin evrensel nitelikteki belli gerçeklere göre şekillendirilmesi ve insanların değişmez bu gerçekler ışığında yetiştirilmesi gerektiğini savunur. Belli başlı bir felsefeye dayanmayan ve doğrudan bir eğitim hareketi olarak ortaya çıkan "Esasicilik" eğitim felsefesine göre bütün insanların sahip olması gereken ve geçmişten gelen temel konu ve değerler korunup öğretilmelidir. Etkili öğrenme ve öğretim ancak bu şekilde sağlanabilir. Öğrenmenin ve öğretimin temelinde "zihin" vardır. Değişmeyi gerçeğin esası olarak gören pragmatik felsefeye dayanan "ilerlemecilik" eğitim felsefesi, eğitimin tecrübenin sürekli olarak yeniden inşa edilmesi ve geçmişteki yaşantılara dayalı olarak, gelecekteki davranışların şekillendirilmesi olduğunu savunur. Son olarak temelini pragmatizm ve varoluşçuluktan alan "Yeniden Kurmacılık" eğitim felsefesi ise eğitimin toplumsal dönüşümün en önemli araçlarından biri olduğunu savunmaktadır (Demirel 2009). Etkin Öğretim, sorgulama ve kavramsallaştırma gibi karmaşık, zor ve ustalık gerektiren becerilerin harekete geçirildiği etkin bir süreci ifade eder (Bliss, Askew ve Macrea, 1996).

Etkili öğrenme ve öğretimi gerçekleştirmek için öğretim ve öğrenmeyi planlayan, uygulayan ve değerlendiren etkili öğretmen yetiştirilmesi amacıyla neler yapılması gerektiğine yönelik tartışma ve öneriler zaman zaman gündeme gelmiştir (Ekiz ve Yigit, 2006). Tartışma ve önerilerde öğretmen adaylarının öğretmeyi nasıl öğrendikleri, öğretim sürecinde neye değer verdikleri, neyi benimsedikleri,

\footnotetext{
*Yazar: mkorumaz@yildiz.edu.tr
} 
hangi bilgiyi (kurama veya uygulamaya dayalı) etkin olarak kullandıkları, kuramsal bilgiyi öğrenmeleri ve kullanmalarına yönelik açıklamalar bulunmaktadır. Çevre, davranış, yeterlilik, düşünce, kişilik ve görev gibi farklı düzeylerde öğretmen karakteri bir uyum içerisinde bulunmalıdır (Korthagen, 2004). Öğretmenlerin işlerini yaparken kullanacakları becerileri, mesleklerine ve becerilerine ilişkin tutumları, mesleki inanışları hizmet öncesinde ve hizmet içinde şekillenmektedir. Bu açından bakıldı̆ıında öğretmenlerin eğitimi, öğretmenlerin beklenen beceri, tutum ve inançlara sahip olması için önemlidir. Öğretmenlerin eğitimi ya da öğretmen yetiştirmeyle ilgili yönelimler geçmişten günümüze büyük oranda değişikliğe uğramıştır. Kısa zaman içerisinde yaşanan bu değişimler bireyi merkeze alan eğitim paradigmalarının bir yansıması olarak kabul edilebilir. Buna paralel olarak son yıllarda öğretmen eğitimi programları çağın gereklerine uygun olarak birey merkezli yapılar haline dönüşmekte ve öğretmen eğitimi programları teoriye dayalı öğretmen merkezli yaklaşımdan daha çok uygulamaya dayalı öğrenci merkezli yaklaşıma doğru kaymıştır (Kılıç, 2006).

Öğretmen yetiştirme modelleri bu yaklaşımın felsefi ve pratik dayanaklara göre oluşturulmuştur. Bu dayanaklar çoğunlukla, öğretmenlik mesleğinin genel olarak araştırmacılar tarafından nasıl algılandığına yöneliktir (Ekiz, 2003). Bazen öğretmenlik, beceriye dayalı bir meslek olarak görülmüş, öğretmen adaylarının deneyimli öğretmenlerden yararlanarak gerekli becerileri kazanması gerektiği vurgulanmıştır. Bazen de öğretmenlik mesleği bilim olarak görülmüş, araştırmalar sonucunda elde edilen bulgular ışığında üretilen bilimsel bilgilerin, öğretmen adaylarından sergilenmesi istenmiştir. Yine öğretmenlik mesleği, bir sanat olarak algılanmış, öğretmen adaylarının yaratıcı olmaları, kendi uygulamalarını sistematik olarak sorgulamaları ve incelemeleri istenmiştir (Ekiz ve Yiğit, 2006). Öğretmenliğin farklı biçimlerde algılanması farklı öğretmen yetiştirme modellerini de beraberinde getirmiştir.

Günümüze kadar yaygın bir şekilde kabul gören öğretmen yetiştirme modelleri; teori merkezli öğretmen yetiştirme modeli, insancıl kurama dayalı öğretmen yetiştirme modeli, yapısalcı kurama dayalı öğretmen yetiştirme modeli ve yansıtma modelidir. Uygulamada ise şimdiye kadar kendini belirgin şekilde gösteren üç genel öğretmen yetiştirme modeli bulunmaktadır. Bunlar; beceri modeli, uygulanmış bilim modeli ve yansitma modelidir (Wallace, 1991).

Beceri modelinin temelinde "yaparak-yaşayarak öğrenme" yaklaşımı bulunur. Bu model, öğretmenlik bilgi ve becerisinin ancak ve ancak gözlem ve deneyimle kazanılabileceğini savunur (Smith, 1999). 1950'li yıllardan itibaren geliştirilmeye ve kullanılmaya çalışılan uygulanmış bilim modeli, uygulamalarını eğitim psikolojisindeki bulgulara dayandırır. Bu model, rasyonel yaklaşım olarak da bilinmektedir (Ekiz ve Yiğit, 2006). Laursen'a (1996) göre bu model, davranışçı psikoloji alanında üretilen öğrenme kuramlarının etkili öğretim metodlarına dönüştürülmesi prensibine dayanır. Bu model, eğitim alanında yapılan bilimsel araştırma verilerinden eğitim-öğretim uygulamalarında yararlanılması gerektiğini savunur.

Yansıtma modeline göre ise öğretmen adayı, kuramsal olarak öğrendiği bilgi ve öğretmenlik deneyimine yönelik kazandığı bilgi ve becerilerini uygulamada etkin olarak kullanır. Hem kuramsal olarak öğrendiği hem de deneyimlerinden oluşturduğu bilgiden yararlanan aday, herhangi bir okul ya da sınıf ortamında uygulama yapar. Uygulamada karşılaştığı herhangi bir sorunu, edindiği kuramsal bilgileri de göz önüne alarak, sorunu ortadan kaldırmak ya da uygulamayı daha etkili hâle dönüştürmek için etkin, ısrarlı ve sistematik bir biçimde etraflıca düşünür. Düşünme sonucunda yapılandırdığı yeni bilgi ve becerileri tekrar uygulamada kullanır. Aynı şekilde bu döngü devam eder. Yansıtııı düşünme ve öğretimi gerçekleştirdikten sonra profesyonel (mesleki) yeterliliği kazanır ve öğretmen olur (Ekiz, 2003). Yansıtıcı modelin en belirgin özelliği, hem bilimsel araştırmalara dayalı bilgilerden yararlanılması hem de bu bilgilerin uygulamaya aktarılırken sorgulanarak öğretmen ya da aday öğretmen tarafından karar verme sürecine dahil edilmesidir (Ekiz ve Yiğit, 2007).

1930'lu yıllarda John Dewey yansıtıcı öğretimi, uygulamaların ve inançların kökenleri ve etkilerinin sürekli ve aktif bir biçimde sınanması olarak tanımlamıştır (Stanley, 1998). Çünkü önceki yaşantımız ve öğretimle ilgili edindiğimiz inançlar ve doğrular, öğretimimizin şekillenmesini doğrudan etkilemektedir. 
Pennington (199) ise yansıtıcı öğretimi "Deneyimler hakkında derinlemesine düşünülmesi ve bu deneyimlerin yansıması" (s. 47) olarak tanımlamaktadır. Cruickshank ve Applegate (1981)'e göre ise öğretmenler, öğretim sürecinde ne meydana geldiğini, niçin meydana geldiğini, daha etkili bir öğretim için neyin yapılabilir fakat yapılmamış olduğunu ve öğretim performanslarının geliştirilmesi için ne gibi değişikliklerin yapılması gerektiği ile ilgili düşünmelerinde yardım edilebilmesi için bir araç olarak yansıtıcı öğretimi kullanırlar. Öğretmenler araştırma süreçlerinde sadece öğretmen olarak değil aynı zamanda araştırmacı olarak da yer almak durumundadırlar (Altrichter, Feldman, Posch, ve Somekh 2008; Carr ve Kemmis, 1986). Dewey'e göre eğer bir kişi yansıtıcı öğretim ile ilgileniyorsa üç tutuma sahip olması gerekir; açık fikirlilik, sorumluluk alabilme ve açık yüreklilik (Akt: Cook, 1998).

Yansıtma kavramıyla ilgili son zamanlarda birçok araştırma ve çalışma yapılmıştır. Ama bu kavram ve bu kavramdan temelini alan yansıtıcı öğretim ile ilgili yapılan çalışmalar genel olarak öğretmen adayları ve öğretmenlerle ve ilk ve ortaöğretim kurumlarıyla sınırlı kaldığı için yeterli değildir (örn: Amobi, 2005; Filiz, 2008; Karadağ, 2010; Lee, 2007; Pedro, 2005). Schön (1983) başlangıçta yansıtmanın iki türü olan; "eylem hakkında (öğretim hakkında) yansıtma" ve "eylemde (öğretimde) yansıtma" üzerinde yoğunlaşırken sonradan üçüncü bir tür olan "eylem için (öğretim için) yansıtma" kavramını ortaya atılmıştır. Eylem (öğretim) hakkında yansıtma, öğretim eyleminin gerçekleşmesinin ardından sonraki eylemlere ışık tutması ya da sonraki eylemlerin planlanması için uygulanmış olan öğretim eyleminin sistematik ve tutarlı bir süreç içerisinde yansıtılmasıdır. Bu yansıtma türünde önemli olan nokta yansıtmanın öğretim eyleminin hemen ardından yapılmasıdır (Schön, 1983). Eylemde (öğretimde) yansıtma, öğretim eylemine aktif bir biçimde devam ederken yapılan yansıtma ve karar kılma sürecini ifade etmektedir. Schon (1987)' e göre eylemde yansıtma sınıf içinde öğretim gerçekleşirken onunla ilgili düşünülüyor olmasıdır. Bu durumda yansıtma bağlam temellidir (Day, 1999). Öğretmenin içinde bulunduğu bağlamı göz önüne alarak değerlendirmede bulunması oldukça önemlidir. Bu yapıyor olduğumuz işle ilgili düşünmekten çok daha fazlasını ifade etmektedir. Anlık analiz ve muhakeme yeteneğini gerektirir ve bu yüzdendir ki birçok eğitimci ve araştırmacı bu tür öğretimin ve uygulamanın çok daha zor olduğu kanısındadır (Waters, 2005). Eylem (öğretim için) için yansıtma yansıtıcı uygulamalar yapmak isteyenlere şimdiye kadar edindiklerini anımsamaları ve sonraki bölümlerde neler yapacaklarını daha bilinçli bir şekilde planlamaları için olanak sağlayabilecek bilişsel bir süreci ifade etmektedir. Bu tür yansıtmada ideal olan, eleştirel pedagojiyi ve öğretmenlerin öğretimle ilgili farklı bakış açılarını analiz etmelerine olanak tanıyan pedagojik teorileri de içermesidir (Weshah, 2007).

Yansıtıcı öğretim alanları ise; teknik, uygulama ve eleştirel olmak üzere üç farklı alanı ifade etmektedir. En temel yansıtıcı öğretim alanı teknik yansıtma alanıdır. Kuram ve uygulamaya ilişkin bilginin artması, yansıtıcı öğretim alanlarının genişlemesi ve üst düzey yansıtma alanları olan uygulama ve eleştirel yansıtmaya geçişte ön şart olarak kabul edilmektedir (Taggart, 2005).

Yansıtıcı öğretim, öğrenme-öğretme ortamında olanlar üzerinde düşünüp eylemlerde bir takım değişikliklere gitmek olarak tanımlandığına göre, hem öğretmenlerin hem de öğrencilerin öğrenme/öğretme ortamları hakkında veri toplamaları gerekmektedir. Yansıtma için veriler farklı yansıtıcı öğretim araçlarıyla toplanır. Söz konusu yansıtıcı öğretim araçları tek tek kullanılabileceği gibi derinlemesine bilgi elde edilebilmesi için bir arada da kullanılabilir. Yansıtıcı öğretimin veri toplama araçlarından bazıları şunlardır: Öğretim günlükleri, ders raporları, araştırma ve anketler, eylem araştırmaları, gözlem, ses ve görüntü kayıtları, meslektaş danışması ve öğretim tartışmaları (Richards, 1995).

Son zamanlarda yansıtıcı öğretimin türleri, alanları ve yansıtıcı öğretim araçlarının kullanımına yönelik çalışmaların sayısı tüm dünyada hızla artmaktadır. Yapılan çalışmaların sayısındaki artış yansıtıcı öğretimin giderek önem kazandığını göstermektedir. Bu çalışmalardan bazıları yükseköğretim kurumlarında çalışmakta olan öğretim görevlilerinin görüşlerine başvurmuştur. Örneğin, Amobi (2005) üniversitelerin eğitim fakültelerinde görev yapan öğretim görevlilerinin yansıtıcı öğretim kavramını nasıl tanımladıklarını ortaya koymaya çalıştığı çalışmasının sonuçlarına göre öğretim elemanları yansıtıcı 
öğretimi genel olarak "öğretime bir ayna tutmak" "bir şeylere farklı açıdan bakmak konusunda korkusuz olmak ve korkusuz olmaya istekli olmak" şeklinde tanımladıkları görülmüştür.

Pedro (2005) öğretmen adaylarının yansıtma kavramına yönelik tutumları üzerine yaptı̆̆ı çalısmasında öğretmen adaylarının yansıtma sürecinde geriye dönük değerlendirmeleri farklı algıladıkları ortaya çıkmıştır. Bir grup bunun sadece geriye dönüp bakma olarak nitelerken diğer grup yapılabilecek değişiklikler için bir yansıtma olduğunu düşünmektedir. Öğretmen adaylarına göre yansıtma kişinin kendisi tarafından öğrenilmekte, eylem sonrasında ve eylem için yapılmakta ve kişisel inançlara ve eğitimle ilgili teorilere dayanmaktadır. Aynı zamanda öğretmen adaylarının yansıtmayı öğretim tekniklerinin bir tamamlayııısı ve yardımcı bir aracı olduğu yönünde genel bir algıya sahip oldukları sonucuna da ulaşıımışır.

Lee (2007) öğretim günlüklerinin üniversitede çalışan İngilizce öğretmenlerinin yansıtma becerilerine faydasını belirlemeye çalışı̆̆ı araştırmasının sonucunda, diyalog içeren günlüklerin, öğretmenlerin yansıtıcı düşünme ile iç içe olmalarına yardım ettiği ortaya konmuştur. Diğer yandan öğretmenler yansıtııı günlükler vasıtasıyla tecrübelerini paylaşabildiklerini belirtmişlerdir.

Filiz (2008) "İngilizce Öğretmenlerinin Yansıtıcı Öğretime Yaklaşımları" isimli çalışmasında İngilizce öğretmenlerinin, mesleki gelişimin bir parçası olan yansıtıı öğretime yaklaşımlarını ortaya koymayı amaçlamıştır. Çalışmanın sonucunda, öğretmenlerin çoğunluğunun yansıtıcı öğretime yönelik yaklaşımlarının olumlu olduğu görülmüştür. Çalışmadan çıkan bir diğer sonuç da, tecrübeli öğretmenler ile tecrübesiz öğretmenlerin yansıtıcı öğretime yaklaşımlarında önemli farklılıklar bulunmasıdır. Bu çalışma çerçevesinde tecrübeli öğretmenlerin yansıtıcılık kavramının farkında oldukları ve gerekliliğine inandıkları görülürken diğer taraftan tecrübesiz öğretmenlerin yansıtııılı̆ı̆n gerekliliğine inanmakta tereddüt ettikleri görülmektedir.

Karadağ (2010) "Sosyal Bilgiler Öğretmenlerinin Yansıtıcı Düşünme Düzeylerinin İncelenmesi" isimli çalışmasında sosyal bilgiler öğretmenlerinin yansıtıcı düşünme düzeylerinin oldukça yüksek, yansıtıcı düşünme becerileri ile ilgili en olumlu algılarının ise "Açık Fikirlilik" boyutunda olduğu sonucuna ulaşmıştır.

Sonuç olarak, günümüzde bireylerin sadece bilgi sahibi olması ve eylemde bulunması toplumun bireyden ve bireyin öz yeterlikleriyle ilgili kendi beklentilerine cevap vermekte yetersiz kalmaktadır. Bireyden beklenen, yeterli bilgiye sahip olması, özgün eylemlerde bulunması ve eylemlerinin etkililiğini değerlendirip yeni eylemlerini bu değerlendirmelere göre düzenlemesidir. Bu olgu bireyler için öğrenilebilir bir süreci ifade etmektedir (Pennington, 1992).

Yansıtıcı öğretim, öğretmenlerin neyi, niçin, nasıl yaptıklarını eleştirel bir biçimde analiz etmeleri ve kendi öğretim performanslarını iyileştirmeleri için kullandıkları amaçlı bir süreçtir (Serafini, 2002). Öğretmenler yansıtıcı öğretim sayesinde, eylem (öğretim) öncesinde etkinlikleri geçmiş yaşantıları doğrultusunda planlayabilmekte, uygulama (öğretim) sırasında kendi eylemlerini kontrol altında tutabilmekte ve eylemleriyle (öğretim) ilgili değerlendirme yapabilmek için gerekli olan bilgiyi toplayabilmektedir. Öğretmenler yansıtıcı öğretim sayesinde edindikleri bilgi ve deneyimlerini mesleki gelişimleri doğrultusunda kullanma imkanı bulmaktadırlar (Pennington, 1992). Öğretmenlerin yansıtıcı öğretime yönelik tutumlarının olumlu ya da olumsuz olması öğretmenlerin mesleki gelişimleri ve öğrencilere sundukları öğrenme yaşantıları açısından önemli görülmektedir.

Yukarıda bahsedilen nedenlerden dolayı, yansıtıcı öğretimin günümüz öğretmenlik mesleği açısından önemi göz önünde bulundurularak İngilizce okutmanlarının yansıtıcı öğretime ve alt boyutlarına yönelik tutumlarının bireye özgü ve örgütsel değişkenler açısından belirlenebilmesinin eğitim bilimleri alanına katkı sağlayacağı düşünülmüştür. Tahmin edilen katkıların başında şunlardan bahsedilebilir: öğretmen yetiştirme programlarına ışık tutabilir ve hem öğrenci ve öğretim üyelerinde kendi eğitim ve öğretim 
faaliyetleri hakkında bir 'farkındalık' ve 'bilinçlenme' hissi uyandırabilir. Hatta bu çalışmada kullanılan veri toplama amacındaki maddeler okutmanların kendilerini mesleki faaliyetleri ve eğitim öğretim eylemleri açısından sorgularına ve bunlar üzerine tekrar kafa yormalarına neden olmuş olabilir.

\section{Problem}

Bu çalışmanın problemi, 2011-2012 eğitim-öğretim yılında özel ve devlet üniversitelerinde görev yapmakta olan İngilizce okutmanlarının yansıtıcı öğretime ve alt boyutlarına yönelik tutumlarının bireye özgü ve örgütsel değiş̧enler açısından belirlenmesidir. Çalışmanın alt problemleri ise;

1. Türkiye'deki özel üniversiteler ve devlet üniversitelerinde görev yapan İngilizce okutmanlarının yansıtıcı öğretime yönelik tutumları cinsiyetlerine göre anlamlı bir farklılık var mıdır?

2. Özel ve devlet üniversitelerinde görev yapan İngilizce okutmanlarının yansıtıcı öğretime yönelik tutumları görev yaptıkları kuruma göre anlamlı bir farklıık göstermekte midir?

3. Özel ve devlet üniversitelerinde görev yapan İngilizce okutmanlarının yansıtıcı öğretime yönelik tutumları arasında mezun oldukları fakülte türüne göre anlamlı bir farklıık var mıdır?

4. Özel üniversiteler ve devlet üniversitelerinde görev yapan ingilizce okutmanlarının yansıtıcı öğretime yönelik tutumları arasında en son mezun oldukları program türüne göre anlamlı bir farklıık var mıdır?

\section{Amaç}

Çalışmanın amacı, 2011-2012 eğitim-öğretim yılında özel ve devlet üniversitelerinde görev yapan İngilizce okutmanlarının yansıtıcı öğretime yönelik tutumlarını bireye özgü ve örgütsel değişkenler açısından ortaya koymaktır. Araştırmada İngilizce öğretmenlerinin yansıtıı öğretime yönelik tutumlarını etkileyen ve şekillendiren cinsiyet, mezun oldukları fakülte türü ve görev yaptıkları kurum türünün okutmanların yansııııı öğretime yönelik tutumlarıyla olan ilişkisinin açıklanması amaçlanmaktadır.

\section{Önem}

$\mathrm{Bu}$ araştırma sonucunda elde edilecek veri ve sonuçlar doğrultusunda;

- Okutmanların mezun olunan fakülte türü, çalışılan kurum türü, gibi kontrol edilebilen değişkenlerin İngilizce okutmanlarının tutumlarında yol açtığı farklılıkların açıklığa kavuşturulacağı,

- Araştırmanın bu konuda çalışacak diğer araştırmacılara kaynak teşkil edeceği,

- Öğretmen yetiştiren kurumların öğretim programlarının geliştirilmesine katkı sağlayacağı düşünülmüştür.

\section{Sınırlıklar}

Araştırma, çalışmaya katılan İngilizce okutmanları ve bu okutmanların veri toplama aracına verdikleri cevaplar ile sınırlıdır. Diğer bir sınırlıık ise yansıtıcı öğretimin ölçekte yer verilen boyutlar, kullanılan veri toplama yöntemleri bakımından tanımlanmasının araştırmayı daha zenginleştireceği düşüncesidir. Ayrıca, çalışmadaki bulgular sadece çalışmada yer alan katılımcılar için genellenebilir. Bu nedenle, sonuçları başka bir ildeki kurumlara yani hem özel hem de devlet üniversitelerinde görev yapan okutmanlara genellemek mümkün değildir.

\section{Sayıltılar}

Araştırmaya katılan tüm İngilizce okutmanlarının soruları içten ve doğru yanıtladıkları varsayılmaktadır. Bununla beraber, araştırma ölçeğinin katılımcılar tarafından kendi başlarına cevaplanacak şekilde tasarlanmasının cevaplardaki samimiyeti arttırdığı farz edilimiştir. Çünkü çünkü bu aracın bir açıklama kapasitesi olduğu düşünülmektedir. 


\section{Yöntem}

\section{Araştırma Modeli}

Yapılan çalışma betimsel bir araştırma olup araştırmada tarama modeli kullanılmıştır. Tarama modelleri, geçmişte ya da halen var olan durumun var olduğu şekliyle betimlemeyi amaçlayan araştırma yaklaşımıdır. Araştırmaya konu olan olay, birey ya da nesne kendi koşulları içinde olduğu gibi tanımlanmaya çalışılır (Karasar, 2008). Bu araştırmada İngilizce okutmanlarının yansıtıcı öğretime yönelik tutumları belirlenmeye çalışılmıştır.

\section{Katılımcılar}

Araştırmanın evrenini Türkiye'deki özel ve devlet üniversitelerinde görev yapan İngilizce okutmanları oluşturmaktadır. Örneklem ise 6 özel (Piri Reis, Başkent, Maltepe, Bahçeşehir, İzmir, Zirve üniversitesi) ve 11 devlet (Erzincan, Süleyman Demirel, Gazi, Nevşehir, Karabük, Akdeniz, Yıldız Teknik, Kırklareli, Atatütk, Bülent Ecevit ve Mehmet Akif Ersoy Üniversiteleri) üniversitesinde görev yapan 56 İngilizce okutmanından oluşmaktadır. Katılımcı sayısının sınırlı olmasından dolayı araştırma sonuçlarının daha geniş bir evrene genellenmesi uygun olmayabilir. Katılımcıların \%32.1'i (18 kişi) erkek ve \%67.9'u (38 kişi) kadındır. Okutmanların \% 60.7'si (34 kişi) devlet üniversitelerinde görev yaparken \% 39.3 'ü (22 kişi) özel üniversitelerde çalışmaktadır. Çalışma gurubunda yer alan İngilizce okutmanlarının \% 62.5 'i (35 kişi) eğitim fakültesi mezunudur. \% 37.5'i (21 kişi) ise fen-edebiyat fakültesi mezunu İngilizce okutmanlarıdır. Ingilizce okutmanlarının \%75'i (42 kişi) lisans düzeyinden mezun iken \%25'i (24 kişi) yüksek lisans mezunudur. Çalışma gurubunu oluşturan İngilizce okutmalarından 1 - 5 yıl arası mesleki kıdeme sahip okutmanların oranı \% 69.6 (39 kişi), 6 ve daha fazla mesleki kıdeme sahip okutmanların oranı \% 30.4'tür (17 kişi). Okutmanların ders okuttukları sınıfların mevutları göz önüne alındığında ise katılımcıların \% 55.4’ü (35 kişi) 1 -20 kişilik sınıflarda, \%26.8 ‘ (16 kişi) 20 - 30 kişilik sınıflarda ve \% 16.1 ‘ ( 9 kişi) 31 ve üstü mevcuda sahip sınıflarda ders okutmaktadır.

\section{Veri Toplama Araçları}

\section{Yansıtıcı öğretime ilişkin tutum ölçeği}

Araştırma betimsel nitelikte bir çalışmadır. Araştırmada Akbari, Bahzadpoor ve Dadvand (2010) tarafından geliştirilen ölçek kullanılmıştır. Ölçek, Korumaz (2012) tarafından Türkçe'ye uyarlanmıştır. Ölçekte beş alt boyuta yönelik toplam 29 madde yer almaktadır. Maddeler beşli likert tipindedir. Ölçekte asgari 29 ve azami 145 puan alınabilmektedir. Puanların belirlenen aralıklara göre dağılımı ise şu şekildedir: 29 - 52 arası puanlar "Hiç (1.00-1.79)", 53 - 75arası puanlar "Nadiren (1.80 - 2.59)", 76 - 98 arası puanlar "Bazen (2.60 - 3.39), 99 - 121 arası puanlar "Sık sık (3.40 -4.19) ve 122 - 145 arası puanlar "Her zaman (4.20 - 5.00)" basamağında yer almaktadır.

Bu çalışmada Korumaz'ın (2012) ulaştığı sonuçlar göz önünde bulundurulmuş ve araştrımacının yaptığı yapı geçerliği analiz sonuçları dikkate alınmıştır. Bu bağlamda, bir konuda deneklerden elde edilen yanıtlardan değişkenler arasındaki korelasyonun hesaplanması, aralarında ilişki bulunan ve aynı boyutu ölçen değişkenlerin gruplandırılması işlemi sonucunda faktörler belirlenmektedir. Bu analiz belirli bir konuyu ölçmek amacı ile hazırlanmış olan ölçeğin yapı geçerliliğini göstermektedir (Ural ve Kılıç, 2005). Ölçeğin yapı geçerliğine kanıt sağlamak ve ölçeğin faktör yapısını incelemek için temel bileşenler faktör analizi uygulanmış ve madde seçme ve maddenin uygunluğuna ilişkin karar vermeye dayanak sağlayan kriter faktör yük değeri 0.30 ve üzeri olarak alınmıştır. Ayrıca, öz değeri 1'den büyük olan faktörler üzerinde işlem yapılmıştır (Tabachnick ve Fidell, 2001).

Öncelikle faktör analizini uygulanacak veri setinin analiz için uygunluğunun değerlendirilmesinde Kaiser-Mayer-Olkin (KMO) uygunluk testi ve Barlett testi kullanılmıştır. KMO testi, değişkenler arasındaki korelasyonları ve faktör analizinin uygunluğunu ölçen uygunluk testidir. Testin değeri 0-1 arasında değişmektedir. KMO değeri, herhangi bir değişkenin diğer değişkenler tarafından hatasız tahmin 
edilmesi durumunda 1'e eşit olur (Cengiz ve Kılınç, 2007). Bu araştırmada veri setinin analiz için uygunluğunu belirlemek amacıyla yapılan KMO ve Barlett testi sonuçları; KMO testi \% 82 ( .82) çıkarak veri setinin analiz için uygun olduğunu göstermiştir ayrıca Barlett testi de $(p<.01)$ anlamlı çıkmıştır. Değişkenler arası korelasyonun mevcut olduğu sonucuna ulaşılabilir. Ölçekle ilgili yapılan bu analizlerin sonuçları aşağıda Tablo 1'de verilmiştir.

Tablo 1.

KMO ve Barlett Testi Sonuçları.

\begin{tabular}{lr}
\hline Kayser-Meyer-Olkin örnekleme ölçüsü & .82 \\
Bartlett's Test of Sphericity Approx. Chi-square & $1.641 E 3$ \\
$D f$ & 406 \\
Sig. & .000 \\
\hline
\end{tabular}

Varimax rotasyon yöntemi kullanılarak yapılan temel bileşenler faktör analizi işlemi sonucunda özdeğerleri 1'den büyük 5 faktör elde edilmiştir. Bu beş faktör toplam varyansın \%65'ini açıklamaktadır. Ölçme aracının Akbari, Behzadpoor ve Dadvand (2010)'ın çalışmalarına paralel olarak beş alt boyuttan oluştuğu tespit edilmiştir. Çalışmanın alt boyutları; Yansıtıcı öğretimin içerdiği öğretim günlükleri, ders raporları, araştırma ve anketler, gözlem grup tartışması gibi araçlar ve yansıtıcı uygulamalarla ilgili olan uygulama boyutu ( Iilgili Maddeler: 1, 2, 3, 4, 5, 6,), mesleki gelişimine yönelik çabaların olduğu, küçük çaplı sınıf içi araştırmalar (Eylem Araştırmaları), alanıyla ilgili konferans ve seminerlere katılma, alanıyla ilgili gelişmeleri takip etmeyi içeren bilişsel boyut ( İlgili Maddeler: 7, 8, 9, 10, 11, 12), Öğretmenin öğrencileri ile ilgili yaptığı yansıtmaları, öğrencilerin nasıl öğreniyor oldukları ve sınıf içerisindeki tutum ve davranışlarını belirlemeye yönelik maddelerin yer aldığı Öğrenci Boyutu ( İlgili Maddeler: 13, 14, 15,) , öğretmenin kişiliği ve mesleğe yönelik inançları, kendi uygulamalarını ve tutumlarını nasıl tanımladığı ile ilgili üst biliş boyut ( IIlgili Maddeler: 16,17, 18, 19, 20, 21, 22), pedagojinin sosyo-politik yönleriyle ve bu sosyo-politik yönlerle ilgili yansıtma eyleminin yapıldığı maddelerini kapsayan, öğretmenlerin uygulamalarında politik önem taşıyan yanlar ve ırk, cinsiyet, sosyal sınıf gibi konuları içeren eleştirel boyut ( Illgili Maddeler: 23, 24, 25, 26, 27, 28, 29.). Bu boyutlar aynı zamanda farklı yansıtma alanlarını temsil etmektedir. Uygulama boyutu, "uygulama yansıtma alanını", bilişsel boyut ve öğrenci boyutu, "teknik yansıtma alanını" ve üst biliş boyutu ve eleştirel boyut “ eleştirel yansıtma alanını" temsil etmektedir.

I.Boyut olan uygulama boyutu için Cronbach's Alpha $\alpha>0.701$ bulunmuştur. II. Boyut olan bilişsel boyut için Cronbach's Alpha değeri $\alpha>0.834$ bulunmuştur. III. Boyut olan öğrenci boyutu için ise Cronbach's Alpha değeri $\alpha>0.636$ bulunmuştur. IV. Boyut olan üst biliş boyutu için Cronbach's Alpha değeri $\alpha>0.839$ bulunmuştur. V. Boyut olan eleştirel boyutu için Cronbach's Alpha değeri $\alpha>0.775$ bulunmuştur (Korumaz, 2012). Toplam 29 madden oluşan ölçme aracının güvenirlik katsayısı $\alpha=0.915$ olarak hesaplanmıştır.

\section{Verilerin Toplanması}

Araştırmada kullanılan veri toplama aracı katılımcılara araştırmacılar tarafından online anketler halinde uygulanmıştır. Bunun için Google belgelerden yararlanılmıştır. Uygulama öncesinde katılımcılara araştırmanın amacına ilişkin bilgi verilmiştir. Uygulama yaklaşık 10-15 dakika arası sürmüştür.

\section{Verilerin Analizi}

Çalışma için elde edilen verilerin analiz edilmesinde SPSS 16. istatistiki analiz programı kullanılmıştır. Analiz testleri uygulanmadan önce normallik testleri yapılmış ve gerekli koşullar sağlandıktan sonra veri betimleyici istatik analizinde istatiksel teknik olarak ilişkisiz örneklem t-testinden yararlanılmıştır. Bulguların yorumlanmasında .05 anlamlılık düzeyi ölçüt alınmıştır. 


\section{Bulgular}

Betimleyici analizler sonucunda elde edilen bulgular, aşağıda alt problemlere göre tanımlanmış ve belirli bir sıraya göre verilmiştir. Bu çalışmada, yapılan betimleyici istatistik analizi sonucunda araştırmaya katılan İngilizce okutmalarının ölçme aracından aldıkların en düşük puanın 75 ve en yüksek puanın 128 olduğu sonucuna ulaşıımışır. Araştırmaya katılan İngilizce okutmanlarının ölçekten aldıkları toplam puanların aritmetik ortalaması 96.77 olarak bulunmuştur. Aynı zamanda araştırmada yer alan özel üniversiteler ve devlet üniversitelerinde görev yapan İngilizce okutmanlarının yansıtıcı öğretime yönelik tutumlarında; cinsiyetlerine, görev yaptıkları üniversitenin özel ya da devlet üniversitesi olmasına, mezun oldukları fakülte türüne ve en son mezun oldukları program türüne göre anlamlı bir farklılık olup olmadığını belirlemek için ilişkisiz örneklem t-testi yapılmıştır. Elde edile sonuçlar aşağıdaki alt problem başlıkları altında sunulmaktadır.

\section{İngilizce Okutmanlarının Yansıtıcı Öğretime Yönelik Tutumları Cinsiyetlerine Göre Anlamlı Bir Farklılık Var midır?}

Analiz sonucunda İngilizce okutmanlarının yansıtıcı öğretime yönelik tutumları arasında cinsiyetlerine göre anlamlı bir farklılık bulunmamışır [ $t(54)=0.241, p>0.05$ ]. Elde edilen analiz sonuçları aşağıda Tablo 2'de detaylı olarak verilmektedir.

Tablo 2.

Cinsiyete Göre Betimleyici Istatistik Analizi Sonuçları.

\begin{tabular}{lcccccc}
\hline Cinsiyet & $\mathbf{n}$ & $\overline{\boldsymbol{X}}$ & $\mathbf{S}$ & $\mathbf{S d}$ & $\mathbf{t}$ & $\mathbf{p}$ \\
\hline Kadın & 38 & 95.29 & 11.866 & 54 & 1.185 & .241 \\
\hline Erkek & 18 & 99.89 & 14.275 & & & \\
\hline
\end{tabular}

İngilizce Okutmanlarının Yansıtıcı Öğretime Yönelik Tutumları Görev Yaptıkları Kuruma Göre Anlamlı Bir Farklılık Göstermekte midir?

İngilizce okutmanlarının yansıtıcı öğretime yönelik tutumları arasında yapılan t-testi sonuçlarına göre görev yaptıkları kurumun özel ya da devlet üniversitesi olmasına göre anlamlı bir farklılık bulunmamıştır $[t(54)=0.246, p>0.05]$. Elde edilen test sonuçları aşağıda Tablo 3' de özetlenmiştir.

Tablo 3.

Çalıştığı Kurum Türüne Göre t-Testi Sonuçları.

\begin{tabular}{lcccccc}
\hline Kurum & $\mathbf{n}$ & $\bar{X}$ & $\mathbf{S}$ & $\mathbf{S d}$ & $\mathbf{t}$ & $\mathbf{p}$ \\
\hline Özel & 34 & 95.06 & 12.704 & 54 & 1.172 & .246 \\
\hline Devlet & 22 & 99.41 & 14.822 & & & \\
\hline
\end{tabular}

\section{İngilizce Okutmanlarının Yansıtıcı Öğretime Yönelik Tutumları Arasında Mezun Oldukları Fakülte Türüne Göre Anlamlı Bir Farklılık Var mıdır?}

Yapılan istatiksel analizler sonucunda İngilizce okutmanlarının yansıtıcı öğretime yönelik tutumları arasında en son mezun oldukları fakülte türüne göre anlamlı bir farklılık bulunmamıştır [t(54)=0.365, p>0.05 ]. Iligili istatiksel sonuçlar Tablo 4'te verilmiştir. 
Tablo 4.

Mezun Oldukları Kurum Türüne Göre t-Testi Sonuçları.

\begin{tabular}{lcccccc}
\hline Fakülte & $\mathbf{n}$ & $\overline{\boldsymbol{X}}$ & $\mathbf{S}$ & $\mathbf{S d}$ & $\mathbf{t}$ & $\mathbf{p}$ \\
\hline Eğitim & 35 & 98.06 & 12.163 & 54 & .914 & .365 \\
\hline Fen-Edebiyat & 21 & 94.62 & 15.822 & & & \\
\hline
\end{tabular}

İngilizce Okutmanlarının Yansıtıcı Öğretime Yönelik Tutumları Arasında En Son Mezun Oldukları Program Türüne Göre Anlamlı Bir Farklılık Var mıdır?

Son olarak t-test sonuçları araştırmaya katılan İngilizce okutmanlarının yansıtıcı öğretime yönelik tutumları arasında en son mezun oldukları fakülte türüne göre de anlamlı bir farklılık olmadığını göstermiştir [ $t(54)=0.801, p>0.05$ ]. Yapılan istatiksel test ve sonuçları aşağıda Tablo $5^{\prime}$ de sunulmuştur.

Tablo 5.

Mezun Oldukları Program Türüne Göre t-Testi Sonuçları.

\begin{tabular}{lllllll}
\hline Program & $\mathbf{n}$ & $\overline{\boldsymbol{X}}$ & $\mathbf{S}$ & $\mathbf{S d}$ & $\mathbf{t}$ & $\mathbf{p}$ \\
\hline Lisans & 42 & 96.50 & 13.486 & 54 & .253 & .801 \\
\hline Lisansüstü & 14 & 97.57 & 14.474 & & & \\
\hline
\end{tabular}

\section{Sonuç, Tartışma ve Öneriler}

Araştırmanın sonucunda elde edilen toplam puanlarının aritmetik ortalaması 96.77 ve tutum puanlarının ortalaması veri toplama aracının tamamı için "bazen (2.57)" aralığındadır. Tutum puanlarının ortalaması göz önüne alındığında İngilizce okutmanlarının yansıtıcı öğretime yönelik tutumlarının olumlu olduğu söylenebilir. Bu bulgular Goodman (1984), Troyer (1989), Loughran (1995), Carter (1998), Butke (2003), McKeny (2006), Filiz (2008) ve Karadağlı (2010)'nın öğretmenlerin ve ya öğretmen adaylarının yansıtıcı öğretime yönelik tutum tutumları ile ilgili çalışmalarıyla tutarlık göstermektedir. Okutmanların yansıtıc öğretime yönelik tutumların olumlu olması öğretmenlerin eylem öncesinde, sırasında ya da sonrasında eylemleri hakkında derinlemesine düşünme ve muhakeme yapma eğiliminde oldukları şeklinde yorumlanabilir. Okutmanların yansıtıcı öğretime yönelik tutumlarının olumlu yönde şekillenmiş olması aynı zamanda okutmanların yansıtıcı düşünme eğiliminde olduklarının ve mesleki gelişime önem verdiklerinin bir göstergesi sayılabilir.

Elde edilen bulgular incelendiğinde İngilizce okutmanlarının cinsiyetlerine göre yansıtıcı öğretime yönelik tutumlarında istatistiksel olarak anlamlı bir farklılık bulunmamıştır. Bu çalışmadan elde edilen verilerin aksine daha önce yapılmış çalışmalarda kadın öğretmenlerin erkek meslektaşlarına göre daha yansıtıcı düşündükleri (Aslan, 2009; Çakır, Kan ve Sünbül, 2006; Deniz, Avşaroğlu ve Fidan, 2006; Özcan, 2002;), açık fikirli oldukları (Kaf Hasırcı ve Sadık, 2009; Kılınç, 2010), mesleklerini daha olumlu algıladıkları (Kılınç, 2010) ve iş doyumlarının daha yüksek olduğu (İnce, 2006) görülmektedir. Kadınların öğretmenlik mesleğini tercih ederken erkek öğretmenlerden daha bilinçli davrandıklarını (Çelenk, 1988; Övet, 2006) ortaya koyan bulgular benzer sonuçları sunmaktadır. Karadağlı (2010) kadın öğretmenlerin sorgulayıcı ve etkili öğretim, öğretim sorumluluğu ve bilimsellik, araştırmacılık, öngörülü ve içten olma boyutlarında daha yüksek yansıtıcı düşünme eğiliminde olduğunu ve mesleklerini daha olumlu algıladıkları sonucuna ulaşmıştır.

Elde edilen bulgular incelendiğinde İngilizce okutmanlarının görev yapmakta olduğu kurum türüne göre yansıtıcı öğretime yönelik tutumlarında istatistiksel olarak anlamlı bir farklılık bulunmamıştır. Bu 
bulguya paralel olarak Korkmaz (2008) öğretmenlerin eleştirel düşünme becerileri üzerine yaptığı araştırmasında öğretmenlerin görev yaptıkları kurum türünün öğretmenlerin eleştirel düşünme eğilim ve becerileri üzerinde etkili olmadığı sonucuna ulaşmıştır. Bu çalışmalardan hareketle okutmanların hangi tür kurumda görev yaparlarsa yapsınlar edindikleri öğretimsel becerilere yönelik tutumlarının farklılık göstermediği sonucuna ulaşılabilir.

Araştırmanın sonucuna göre İngilizce okutmanlarının mezun oldukları lisans türüne göre yansıtıcı öğretime yönelik tutumlarında istatistiksel olarak anlamlı bir farklılık bulunmamıştır. Öğretmenlerin fenedebiyat ya da eğitim fakültesi mezunu olma durumlarına göre yapılan benzer çalışmalarda ise farklı sonuçlara ulaşıldığı görülmektedir. Öztürk, Doğan ve Koç (2005) yaptıkları çalışmada eğitim fakültesi mezunlarının öğretmenlik mesleğine yönelik algılarının fen-edebiyat fakültesi mezunlarına kıyasla daha olumlu olduğunu, Şimşek (2011) Eğitim fakültesi öğrencilerinin fen edebiyat fakültesi mezunlarına göre öğretmenlik mesleği ve mesleki gereklilikler konusunda daha olumlu tutuma sahip olduklarını, ancak mesleğin toplumsal saygınlık boyutunda fen edebiyat fakültesi öğrencilerinin daha yüksek düzeyde katılım gösterdiklerini sonucuna ulaşmışlardır. Yapılan bu çalışmaların aksine Gürbüz ve Kışoğlu (2007) öğretmenlerin öğretmenlik mesleğine yönelik tutumlarının fakülte değişkenine göre farklılaşmadığı, öğretmenlik mesleğini tercih etme nedenlerine göre ise adayların tutumlarında farklılık olduğu tespit etmişlerdir. Sonuç olarak yansıtıcı öğretim tutumlarını okutmanların mezun oldukları fakülte türünden etkilenmediği sonucuna ulaşılabilir.

İngilizce okutmanlarının en son mezun oldukları program türüne göre yansıtıcı öğretime yönelik tutumlarında istatistiksel olarak anlamlı bir farklılık bulunmamıştır. Bu araştırmanın sonuçlarına göre okutmanların lisans ya da yüksek lisans mezunu olmalarının yansıtıcı öğretime yönelik tutumlarında herhangi bir farklılığa neden olmadığı sonucuna ulaşılabilir. Buna paralel olarak, Mutlu ve Aktan (2011) yaptıkları çalışmada lisan ve yüksek lisans mezunu öğretmenlerin düşünme eğitimi ile ilgili tutumlarını incelemişler ve lisans ve yüksek lisans mezunu öğretmenler arasında düşünme eğitimine yönelik tutumlar arasında anlamlı bir farklılık bulamamışlardır. Çalışma sonucunda aşağıda belirtilen maddeler önerilmektedir:

1. Bundan sonraki çalışmalarda Ingilizce öğretmenlerinin yansıtıcı öğretim becerilerini ne ölçüde kullanabildikleri belirlenebilir ve söz konusu becerilerin arttırılması için çalışmalar yapılabilir.

2. Öğretmenlerin yansıtıcı öğretime yönelik tutumlarını en üst basamağa taşımak için etkili hizmet içi ve hizmet öncesi eğitim programları tasarlanabilir ve uygulanabilir.

3. Bu konuyla ilgili yapılacak çalışmalarda öğretmenlerin ve öğretmen adaylarının yansıtıcı öğretim becerileri ve bu becerileri kullanma düzeyleri incelenebilir.

4. Yansıtıcı öğretim stratejileri uygulamayı ifade etmektedir. Uygulama alanı, sahip olunan olumlu tutumların ve öğretimle ilgili becerilerin kullanılmasıdır. Bu nedenle yansıtıcı öğretimle ilgili yapılacak bilimsel araştırmalar için yansıtıcı öğretim stratejileri tek tek inceleme konusu yapılabilir.

5. Öğretmen yetiştiren kurumların eğitim programlarında yansıtıcı öğretime daha fazla yer verilmesi için çalışmalar yapılabilir. 


\section{Kaynakça}

Altrichter, H. Feldman, A., Posch, P., \& Somekh, B. (2008). Teachers investigate their work: An introduction to action research across the professions (2nd ed.). Londra: Routledge.

Akbari,R. Bahzadpoor, F. \& Dadvand B. (2010). Development of English language teaching reflection inventory. System, 38(2), 211-227.

Amobi, F.A.(2005). Turning the focus on ourselves: teacher education professors' reflectivity on their own teaching. Reflective Practice, 6(2), 311-318.

Aslan, G. (2009). Sınıf öğretmenlerinin yansıtıcı düşünme eğilimleri ile sürekli kaygı düzeyleri arasındaki ilişki. Unpublished master's thesis, Yeditepe Üniversitesi Sosyal Bilimler Enstitüsü, İstanbul.

Bliss, J., Askew, M. \& Macrea, S. (1996). Effective teaching and learning: Scaffolding revisited. Oxford Review of Education, 22(1),37-61.

Butke, M.A. (2003). Reflection on practice: A study of five choral educators' reflective journeys. Unpublished doctoral dissertation, Ohio State University, Ohia.

Çakır Ö. Kan, A. \& Sünbül, Ö.(2006). Öğretmenlik meslek bilgisi ve tezsiz yüksek lisans programlarının tutum ve özyeterlik açısından değerlendirilmesi. Mersin Üniversitesi Eğitim Fakültesi Dergisi, 2(1),3647.

Carr, W. \& Kemmis, S. (1986). Becoming critical: Education, knowledge and action research. Geelong: Deaking University Press.

Carter, C. W. (1998). The use of journals to promote reflection. Action in Teacher Education, 19(4), 3942.

Cook, F.P. (1998). Teacher Reflection in lerner-centered education. Journal for Educational Reform in Namibia, 8(1), 1-8.

Cruickshank, D. \& Applegate, J. (1981). Reflective teaching as a strategy for tender growth. Educational Leadership,1(1), 553-554.

Çelenk, S. (1988) .Eğitim yüksekokulu öğrencilerinin öğretmenlik mesleğine ilişkin tutumları. Unpublished master's thesis, Selçuk Üniversitesi Sosyal Bilimler Enstitüsü, Konya.

Day, C. (1999). Developing teachers: The challenges of life-long learning. London: Falmer Press

Demirel Ö. (2009). Eğitimde program gelişstirme. İstanbul: Pegem Akademi Yayıncılık.

Deniz, M, Avşaroğlu, S. \& Fidan Ö. (2006). İngilizce Öğretmenlerinin öğrencileri motive etme düzeylerinin incelenmesi. İnönü Üniversitesi Eğitim Fakültesi Dergisi, 7(11), 120-135.

Ekiz, D. \& Yiğit, N. (2007). Öğretmen adaylarının öğretmen eğitimindeki modeller hakkındaki görüşlerinin program ve cinsiyet değişkenleri açısından incelenmesi. Türk Eğitim Bilimleri Dergisi, 5(3), 543-557.

. (2006). Öğretmen adaylarının öğretmen eğitimindeki modeller hakkında görüşlerinin farklı programlar açısından incelenmesi. Illkögretim Online, 5(2), 110-122.

(2003). An analysis of the content of ITE curriculum for the primary phase in Turkey: Theoretical underpinnings and practice. Journal of Kastamonu Education Journal, 11(1), 31-52.

Filiz, Y. (2008). Ingilizce öğretmenlerinin yansıtıcı öğretime yaklaşımları. Unpublished master's thesis, Uludağ Üniversitesi, Bursa.

Goodman, J. (1984). Reflection and teacher education: A case study and theoretical analysis. Interchange, 15(3), 9-26. 
Gürbüz, H. \& Kışoğlu, M. (2007). Tezsiz yüksek lisans programına devam eden Fen Edebiyat ve Eğitim Fakültesi öğrencilerinin öğretmenlik mesleğine yönelik tutumları. Erzincan Eğitim Fakültesi Dergisi, $9(2), 12-24$.

İnce, V. M. (2006). Ilköğretim 3, 4, 5, 6, 7 ve 8. sınıf öğrencilerinin yazılı anlatım becerilerinin ölçülmesi ve değerlendirilmesi. Unpublished master's thesis, Muğla Üniversitesi Sosyal Bilimler Enstitüsü, Muğla.

Karadağ, M. (2010). Sosyal bilgiler öğretmenlerinin yansıtıcı düşünme düzeylerinin belirlenmesi. Unpublished master's thesis, Çukurova Üniversitesi, Adana.

Kaf Hasırcı, Ö. \& Sadık, F. (2009). Sınıf öğretmenlerinin yansıtıcı düşünme eğilimlerinin belirlenmesi. 18. Ulusal Eğitim Bilimleri Kurultayı, Sözlü Bildiri, Ege Üniversitesi, Eğitim Fakültesi, 1-3 Ekim 2009, İzmir.

Kılıç A. (2006). Öğretmen adaylarının öğretmenlik becerilerini uygulama ve gözleme düzeyleri. Sosyal Bilimler Dergisi, 16(1), 155-167.

Kılınç, H. H. (2010). Illköğretim birinci ve ikinci kademe öğretmenlerinin yansıtıcı düşünme eğilimleri. Unpublished master's thesis, Fırat Üniversitesi, Sosyal Bilimler Enstitüsü, Elazığ.

Korthagen, F.A.J. (2004). In search of the essence of a good teacher: A more holistic approach in teacher education. Teaching and Teacher Education, 20(1), 77-97.

Korkmaz, Ö. (2008). Öğretmenlerin eleştirel düşünme eğilim ve düzeyleri. Ahi Evran Üniversitesi Kırşehir Eğitim Fakültesi Dergisi (KEFAD) , 10(1), 1-13.

Korumaz, M. (2012). Ingilizce öğretmenlerinin yansıtıcı öğretime yönelik tutumları. Unpublished master's thesis, Uludağ Üniversitesi, Bursa.

Lee, I. (2007). Preparing pre-service English teachers for reflective practice. ELT Journal, 61(4), 321-329.

Loughran, J. (1995). Practising what I preach: Modelling reflective practice to student teachers. Research in Science Education, 25(4), 431-451.

McKeny, T.S. (2006). A case-study analysis of the critical features within field experience that effected the reflective development of pre-service secondary math teachers. Unpublished master's thesis, Ohio State University, Ohio.

Mutlu, E. \& Aktan, E. (2011). Okul öncesi öğretmenlerinin düşünme eğitimi ile ilgili tutumlarının incelenmesi. Türk Eğitim Bilimleri Dergisi, 9(4),799-828.

Övet ,O. (2006). Eğitim fakültesi öğrencilerinin öğretmenlik mesleğini tercih etmelerinde etkili olan faktörlerin belirlenmesi. Unpublished master's thesis, Yeditepe Üniversitesi Sosyal Bilimler Enstitüsü, İstanbul.

Özcan, T. (2002). illköğretim sosyal bilgiler dersinin genel amaçlarının öğretmen görüşleri doğrultusunda değerlendirilmesi: Kilis ilinde bir araştırma. Unpublished master's thesis, Çukurova Üniversitesi, Sosyal Bilimler Enstitüsü, Adana.

Öztürk, B., Doğan, O. \& Koç, G. (2005). Eğitim fakültesi ile fen Edebiyat Fakültesi mezunlarının öğretmenlik mesleğine yönelik algılarının karşılaştırılması. (Gazi Üniversitesi Örneği). Türk Eğitim Bilimleri Dergisi, 3(1), 1-22.

Pedro, J. Y. (2005). Reflection in teacher education: Exploring pre-Service teacher's meanings of reflective practice. Reflective Practice, 6(1), 49-66.

Pennington, M. (1992). Reflecting on teaching and learning: A development focus for the second language classroom. In Perspectives on Second Language Classroom Teacher Education. eds. J. Flowerdew, M. Brock, and S. Hsia. Kowloon: City Polythenic of Hong Kong.

Richards, J. C. (1995). Reflective teaching in second language classrooms. Cambridge University Press 
Schön, D. (1983) The reflective practitioner. How professionals think in action, London: Temple Smith (1987). Educating the reflection practitioner: Towards a new design for teaching and learning in the profession. San Francisco, CA:Josey-Bass Publishers.

Serafini, F. (2002). Reflective practice and learning. Primary Voices K-6, 10(4), 2-7.

Smith, E. (1999). Ten years of competency-based training: The experience of accredited training providers in Australia. International Journal of Training and Development, 3(2), 106-117.

Stanley, C. (1998). A framework for teacher reflectivity. TESOL Quarterly, 32(3), 584-591.

Şimşek, H. (2011). Ortaöğretim alan öğretmenliği tezsiz yüksek lisans programına devam eden öğrencilerin öğretmenlik mesleğine yönelik tutumları. Yüzüncü Yıl Üniversitesi, Elektronik Eğitim Fakültesi Dergisi, 2(1), 1-26.

Tabachnick, B. G. \& Fidell LS. (2011). Using multivariate statistics. (5th ed.). Boston, MA: Allyn and Bacon.

Taggart, G. (2005). Promoting reflective thinking in teachers: 50 action strategies by Germaine Taggart. Thousand Oaks, CA: Corwin Press.

Troyer, M. B. (1989). The effects of reflective teaching and supplemantal theoritical component on preservice teachers' reflectivity in analysing classroom teaching situation. Unpublished doctoral dissertation, Ohio State University, Ohio.

Ural, A. \& Kılınç, i. (2005). Bilimsel arastırma süreci ve SPSS 'le veri analizi. Ankara: Detay Yayıncllık.

Wallace, M. (1991). Training foreign language teachers. Cambridge: Cambridge University Press.

Waters, M. (2005). Schön and reflective rractice. Erişim Tarihi: 10/05/2012 http://www.resources.scalingtheheights.com/Schon\%20and\%20Reflective\%20Practice.htm

Weshah A.H. (2007). Training pre-service teacher education on reflective practice in Jordanian Universities. European Journal of Scientific Research, 18(2), 206-219. 
Mithat Korumaz ve Ali Karakaş - Pegem Eğitim ve Öğretim Dergisi, 4(1) 2014, 27-46 